\title{
Notified dengue deaths in Myanmar (2017-18): profile and
}

\section{diagnosis delays [version 1; peer review: 2 approved, 1}

\section{approved with reservations]}

\author{
Nwe Ni Linn (1D1, Khine Wut Yee Kyaw (iD),3, Hemant Deepak Shewade (iD3,4,

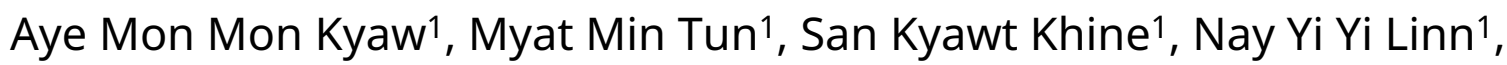 \\ Aung Thi ${ }^{1}$, Zaw Lin ${ }^{1}$ \\ ${ }^{1}$ Vector Borne Disease Control Programme, Department of Public Health, Ministry of Health and Sports, Nay Pyi Taw, Myanmar \\ 2Department of Operational Research, International Union Against Tuberculosis and Lung Disease (The Union), Mandalay, Myanmar \\ ${ }^{3}$ Center for Operational Research, International Union Against Tuberculosis and Lung Disease (The Union), Paris, France \\ ${ }^{4}$ Department of Operational Research, The Union South East Asia, New Delhi, India
}

V1 First published: 09 Jun 2020, 9:579

https://doi.org/10.12688/f1000research.23699.1

Latest published: 09 Jun 2020, 9:579

https://doi.org/10.12688/f1000research.23699.1

\section{Abstract}

Background: Complications in dengue usually occur between day four and day six after fever onset. Hence, early diagnosis and haematological monitoring are vital. Among all hospital reported dengue deaths in Myanmar in 2017-18, we assessed the i) patient profile, ii) proportion of patients who arrived with a dengue diagnosis at admission and iii) delays in diagnosis after fever onset.

Methods: This was a descriptive study involving secondary data. For all the notified deaths, death investigation forms were not available in prescribed format and therefore, data were extracted from hospital case records.

Results: Of 304 deaths, 184 (60.5\%) were female and 233 (76.6\%) were less than 10 years old. Township level hospitals or below reported 36 deaths $(11.8 \%)$ and the remaining deaths were from higher level facilities. Dengue was diagnosed before admission in 26 (8.5\%) people and 169 (55.6\%) were in shock at admission. Of 208 with date of fever onset recorded, the median diagnosis delay was four (interquartile range-IQR: 3,5 ) days. Patient level delay (median three days) was a major contributor to the diagnosis delay.

Conclusions: Most of the patients who died did not have a diagnosis of dengue before admission. This calls for an urgent review of health system preparedness in peripheral health facilities to suspect, diagnose, monitor, refer and treat dengue in children and patient level factors for better understanding of the reasons of delay. Timely filling of death investigation forms in a prescribed format and quarterly death reviews based on these is recommended.

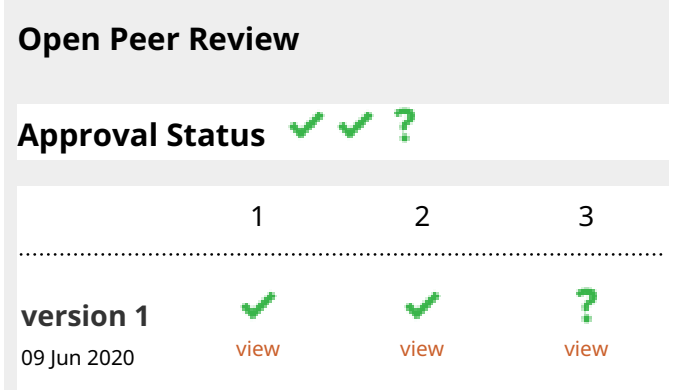

1. Hui Liu, Yunnan Institute of Parasitic Diseases, Puer, China Jian-Wei Xu (D), Yunnan Institute of Parasitic Diseases, Pu'er City, China

2. Zhuo Lin Chong ${ }^{D}$, Ministry of Health, Kuala Lumpur, Malaysia

3. Sangay Zangmo (iD), Ministry of Health,

Thimphu, Bhutan

Lila Maya, Ministry of Health, Thimphu, Bhutan

Any reports and responses or comments on the article can be found at the end of the article. 


\section{Keywords}

Dengue fever, Mortality, Delay in diagnosis, Severe dengue, Operational Research, SORT IT

TDRO

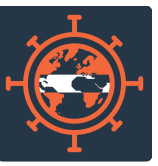

This article is included in the Neglected Tropical

Diseases collection.

Corresponding authors: Nwe Ni Linn (drlinlett@gmail.com), Khine Wut Yee Kyaw (dr.khinewutyeekyaw2015@gmail.com)

Author roles: Linn NN: Conceptualization, Formal Analysis, Investigation, Methodology, Project Administration, Supervision, Validation, Visualization, Writing - Original Draft Preparation, Writing - Review \& Editing; Kyaw KWY: Conceptualization, Data Curation, Formal Analysis, Investigation, Methodology, Project Administration, Supervision, Validation, Visualization, Writing - Original Draft Preparation, Writing - Review \& Editing; Shewade HD: Conceptualization, Formal Analysis, Investigation, Methodology, Supervision, Validation, Visualization, Writing - Original Draft Preparation, Writing - Review \& Editing; Kyaw AMM: Conceptualization, Methodology, Visualization, Writing - Original Draft Preparation, Writing - Review \& Editing; Tun MM: Conceptualization, Methodology, Visualization, Writing - Original Draft Preparation, Writing - Review \& Editing; Khine SK: Conceptualization, Methodology, Visualization, Writing Original Draft Preparation, Writing - Review \& Editing; Linn NYY: Conceptualization, Methodology, Visualization, Writing - Original Draft Preparation, Writing - Review \& Editing; Thi A: Conceptualization, Methodology, Visualization, Writing - Original Draft Preparation, Writing - Review \& Editing; Lin Z: Conceptualization, Methodology, Supervision, Validation, Visualization, Writing - Original Draft Preparation, Writing - Review \& Editing

Competing interests: No competing interests were disclosed.

Grant information: This research was conducted through the Structured Operational Research and Training Initiative (SORT IT), a global partnership led by the Special Programme for Research and Training in Tropical Diseases at the World Health Organization (WHO/TDR). The model is based on a course developed jointly by the International Union Against Tuberculosis and Lung Disease (The Union) and Medecins Sans Frontieres (MSF/Doctors Without Borders). The specific SORT IT programme which resulted in this publication was jointly organised and implemented by The Centre for Operational Research, The Union, Paris, France; Department of Medical Research, Ministry of Health and Sports, Yangon; Department of Public Health, Ministry of Health and Sports, Nay Pyi Taw; The Union Country Office, Mandalay, Myanmar; The Union South-East Asia Office, New Delhi, India and London School of Hygiene and Tropical Medicine, London, UK. The training programme, within which this paper was developed, was funded by the Department for International Development (DFID), London, UK.

The funders had no role in study design, data collection and analysis, decision to publish, or preparation of the manuscript.

Copyright: $\odot 2020$ World Health Organisation. This is an open access article distributed under the terms of the Creative Commons Attribution IGO License, which permits copying, adaptation and distribution in any medium or format for any purpose, provided the original work is properly cited, a link is provided to the license, and any changes made are indicated. Any such copying, adaptation and distribution must not in any way suggest that World Health Organisation endorses you or your use.

How to cite this article: Linn NN, Kyaw KWY, Shewade HD et al. Notified dengue deaths in Myanmar (2017-18): profile and diagnosis delays [version 1; peer review: 2 approved, 1 approved with reservations] F1000Research 2020, 9:579

https://doi.org/10.12688/f1000research.23699.1

First published: 09 Jun 2020, 9:579 https://doi.org/10.12688/f1000research.23699.1 


\section{Introduction}

Dengue is a mosquito-borne viral disease that has rapidly spread in tropical and subtropical regions. Around 3.9 billion people are at risk of dengue in 128 countries where there is good evidence of dengue occurrence ${ }^{1}$. In recent years, transmission has increased predominantly in urban and semi-urban areas and the incidence of dengue in adults is increasing ${ }^{2,3}$. In 2016, there were a total of 3.3 million reported dengue patients ${ }^{4}$.

Severe dengue usually occurs between day four and six after fever onset (called the critical stage, during which fever subsides) and is one of the leading causes of hospitalization and death among children and adults in most Asian and Latin American countries ${ }^{4}$. There are four distinct serotypes of dengue virus (DEN-1, DEN-2, DEN-3 and DEN-4). People who recover from dengue infection may get lifelong immunity against one particular serotype and cross-immunity for a few months. Subsequent infections by other serotypes increase the risk of developing severe dengue ${ }^{4}$. Half a million people with severe dengue require hospitalization every year, and around $2.5 \%$ of them $\mathrm{die}^{4}$. Mortality is highest in younger age groups and reduces with increasing age ${ }^{5}$.

Dengue mortality can be reduced by early detection and good referral systems especially at the primary health care level, predicting and managing severe dengue with appropriate treatment at the hospital level, reorienting health services to cope with dengue outbreaks, and training health personnel at all levels of the health system ${ }^{6}$. Once the diagnosis is confirmed or suspected, severe dengue can be detected early by clinical (significant abdominal pain, persistent vomiting, lethargy, restlessness, mucosal bleeding, fluid accumulation) and haematological monitoring ${ }^{7,8}$.

Delay in diagnosis could be at the level of the patient or health system $^{9,10}$. Late presentation is associated with severe disease in adult dengue patients ${ }^{10}$. Dengue death is commonly associated with co-morbidities and clinicians should be aware if dengue patients fulfil the severe case definition on admission ${ }^{11,12}$.

Myanmar is a high dengue burden country in the Asia Pacific Region. Between 2011 and 2015, of the 89,832 dengue related admissions, $97 \%$ were children ${ }^{13}$. There is limited published literature on diagnosis delays after fever onset among children or adults who died due to dengue. Therefore, we aimed to describe the profile and delays in diagnosis among all dengue deaths in Myanmar.

\section{Methods}

\section{Study design and population}

We conducted a descriptive study involving secondary data collection. We included all dengue deaths reported to the Vector Borne Disease Control (VBDC) Programme in Myanmar during 2017-18.

\section{Setting}

Myanmar, a tropical country, is located in the Southeast Asia Region, bordering the Republic of China on the north and northeast, Laos on the east, Thailand on the southeast,
Bangladesh on the west, and India on the northwest. Myanmar is still a predominantly rural country, with around $30 \%$ of the population living in urban areas ${ }^{14}$. The country is divided administratively into Nay Pyi Taw union territory and 14 states and regions and consists of 74 districts and 330 townships ${ }^{15}$.

Doctors are first available at sub-township level station hospitals. Basic health staff at the level of rural health centres (below station hospital) and sub-centres (below rural health centre) provide comprehensive primary health care. Specialists are available at district level hospitals.

\section{Diagnosis and management of dengue}

SD BIOLINE dengue rapid test kits (includes NS1 Antigen, IgG antibody and IgM antibody) and packed cell volume (PCV) using a centrifuge machine (microhaematocrit or haematocrit) are available at some of the station hospitals. PCV and platelet counts using haematology auto analysers are available at district hospitals and above. The NS1 antigen ELISA test is available only at National Health Laboratory, Yangon, and is used for evaluation of rapid test kits. Diagnosis, treatment and monitoring of dengue patients in health care facilities highly depends on the availability of doctors (at station hospitals), rapid test kits, centrifuge machine and complete haemogram (for platelet count). The laboratory facilities may not be available as assigned or sometimes may malfunction. All the severe or complicated dengue (confirmed or suspected) patients are referred to the nearby district, regional or tertiary hospital.

In 2011, the Myanmar Paediatric Society published Paediatric Management Guidelines (second edition) and updated them in $2018^{16}$. The chapters for dengue were adopted from the 2009, 2011 and 2012 WHO guidelines ${ }^{8,12,17}$. In 2018, the National Guideline for Clinical Management of Dengue for doctors and basic health staff were published ${ }^{18,19}$. Training has been provided to basic health staff and doctors since 2018 in selected states and regions based on funding availability. It is being expanded to the whole country from 2019.

\section{Surveillance of dengue}

The assistant director or team leader is responsible for VBDC Programme planning and implementation at the state and regional levels. All hospitals maintain a dengue register for admitted patients. The VBDC works closely with the department of medical services to collect data on dengue morbidity and mortality by using dengue register. In case of a laboratory confirmed dengue with any grading at hospital, VBDC staff, basic health staff and community volunteers carry out dengue prevention and control activities within a 100 meter radius of the patient's house.

If there is any dengue death, hospitals are expected to inform VBDC staff immediately. VBDC staff go to the hospital and fill out a dengue death investigation form and report back to the central VBDC office.

Dengue patients that do not get admitted are not reported to the VBDC. The dengue patients managed by the private sector are not routinely reported to the programme, except one private hospital which reported one dengue death during 2017-18. 
Variables and data collection

A line list of all dengue deaths was prepared in March 2019 by using the dengue death reports submitted to central VBDC Programme by State and Regional offices. Though we were planning to extract data from death investigation forms, it was found that they were not filled out in the prescribed format. Therefore, data were extracted from the hospital case records to a structured data collection form. These paper-based hospital case records were sent to principal investigator.

The data collected included age, sex, state or region, dengue grading at admission, hospital name, date of admission, type of diagnosis (laboratory/clinical), type of first health care provider visited and cause of death. The dates of onset of fever, first health care provider visited after fever, diagnosis, admission and death were also collected. Operational definitions for ecological regions and dengue grading have been summarized in Table 1.
Data entry and analysis

The data were double-entered and validated using EpiData entry software (version 3.1, EpiData association, Odense, Denmark) and analysed using STATA (version 14.2 College Station, Texas). The profile was summarized using frequencies and proportions. Patient level (fever onset to first health care provider visit), health system level (first health care provider visit to diagnosis) and total diagnosis delay (fever onset to diagnosis) were calculated. The hospital stay duration was calculated from date of admission to date of death. The duration and delays in days were summarized using the median and interquartile range (IQR).

\section{Ethical statement}

Administrative approval for the study was obtained from the VBDC Programme and ethics approval was received from Ethical Review Committee, Department of Medical Research, Myanmar (Ethics/DMR/2018/149 dated 7 December 2018) and

Table 1. Operational definitions used in this study $\mathbf{y}^{3,13,18}$.

\begin{tabular}{|c|c|c|}
\hline \multicolumn{2}{|l|}{ Variable } & \multirow{2}{*}{$\begin{array}{l}\text { Definition } \\
\text { Heavy rainfall more than } 2500 \mathrm{~mm} \text {. Includes Ayeyarwady, Yangon, and Bago regions; Mon } \\
\text { and Kayin states }\end{array}$} \\
\hline Ecological regions & Delta and low land & \\
\hline & Hills & Moderate to heavy rainfall. Includes Kachin, Kayah, Chin, and Shan states \\
\hline & Coastal & Heavy rainfall more than $2500 \mathrm{~mm}$. Includes Rakhine state and Taninthayi regions \\
\hline & Plains & $\begin{array}{l}\text { Uneven topography and rainfall less than } \\
1000 \mathrm{~mm} \text {. Includes Magway, Mandalay, Sagaing, and Nay Pyi Taw regions }\end{array}$ \\
\hline \multirow[t]{6}{*}{ Dengue Grading } & Dengue Fever & $\begin{array}{l}\text { Fever with two of the following } \\
\text { - Headache. } \\
\text { - Retro-orbital pain. } \\
\text { - Myalgia. } \\
\text { - Arthralgia/bone pain. } \\
\text { - Rash. } \\
\text { - Haemorrhagic manifestations Hess* test + > } 70 \% \\
\text { - No evidence of plasma leakage }\end{array}$ \\
\hline & DHF Grade I & $\begin{array}{l}\text { Fever and haemorrhagic manifestation } \\
\text { Hess test }+>90 \% \\
\text { Evidence of plasma leakage }\end{array}$ \\
\hline & DHF Grade II & As in Grade I plus spontaneous bleeding. \\
\hline & DHF Grade III & $\begin{array}{l}\text { As in Grade I or II plus circulatory failure } \\
\text { (weak pulse, narrow pulse pressure ( } \leq 20 \mathrm{mmHg} \text { ), hypotension, restlessness). }\end{array}$ \\
\hline & $\begin{array}{l}\text { DSS (Hypotensive } \\
\text { shock) }\end{array}$ & $\begin{array}{l}\text { As in Grade III plus profound shock } \\
\text { with undetectable blood pressure and pulse }\end{array}$ \\
\hline & $\begin{array}{l}\text { Expanded Dengue } \\
\text { Syndrome }\end{array}$ & $\begin{array}{l}\text { Complications of severe profound shock or associated with underlying host conditions/ } \\
\text { diseases or coinfections. Central nervous system manifestations including convulsions, } \\
\text { spasticity, changes in consciousness and transient paresis have been observed. }\end{array}$ \\
\hline
\end{tabular}

DHF, dengue hemorrhagic fever; DSS, dengue shock syndrome. 
Ethics Advisory Group, The Union, Paris, France (EAG number 45/18 dated 23 August 2018). As this study involved review of routinely collected secondary data, a waiver for informed consent was sought and approved by the ethics committees. This study involved the use of patient medical data in which all data analysed were anonymized.

\section{Results}

Of 31,288 and 23,273 dengue patients hospitalized in 2017 and 2018, $192(0.6 \%)$ and $112(0.5 \%)$ died, respectively.

Patient profile of dengue deaths

The characteristics of these 304 reported deaths at admission and cause of death are described in Table 2. Of 304 deaths, 184

\section{Table 2. Profile of dengue deaths reported to the national} programme in Myanmar (2017-18).

\begin{tabular}{|c|c|c|c|}
\hline \multicolumn{2}{|c|}{ Characteristics } & \multirow{2}{*}{$\begin{array}{r}\mathbf{N} \\
304\end{array}$} & \multirow{2}{*}{$\begin{array}{l}(\%) \\
(100.0)\end{array}$} \\
\hline Total & & & \\
\hline \multicolumn{4}{|c|}{ Age group (years) } \\
\hline & $0-4$ & 110 & $(36.2)$ \\
\hline & $5-9$ & 123 & $(40.5)$ \\
\hline & $10-14$ & 37 & $(12.2)$ \\
\hline & $15-30$ & 24 & $(7.9)$ \\
\hline & $31-45$ & 5 & $(1.6)$ \\
\hline & $>45$ & 5 & $(1.6)$ \\
\hline \multicolumn{4}{|l|}{ Sex } \\
\hline & Male & 120 & $(39.5)$ \\
\hline & Female & 184 & $(60.5)$ \\
\hline \multicolumn{4}{|c|}{ Severity at admission } \\
\hline & DHF grade I & 60 & $(19.8)$ \\
\hline & DHF grade II & 18 & $(5.9)$ \\
\hline & DHF grade III & 47 & $(15.5)$ \\
\hline & DSS & 169 & $(55.6)$ \\
\hline & EDS & 5 & $(1.6)$ \\
\hline & Not recorded & 5 & $(1.6)$ \\
\hline \multicolumn{4}{|c|}{ Type of hospital where death was reported ${ }^{*}$} \\
\hline & Station hospital & 3 & $(1.0)$ \\
\hline & Township hospital & 33 & $(10.9)$ \\
\hline & District hospital & 85 & (28.0) \\
\hline & Regional hospital & 78 & $(25.7)$ \\
\hline & Teaching hospital & 19 & (6.3) \\
\hline & Tertiary hospital & 85 & $(28.0)$ \\
\hline & Private hospital & 1 & $(0.3)$ \\
\hline \multicolumn{4}{|c|}{ Ecological region } \\
\hline
\end{tabular}

\begin{tabular}{|c|c|c|}
\hline Characteristics & $\mathbf{N}$ & (\%) \\
\hline Delta and lowland & 165 & $(54.3)$ \\
\hline Hills & 29 & $(9.5)$ \\
\hline Coastal & 40 & $(13.2)$ \\
\hline Plains & 70 & $(23.0)$ \\
\hline \multicolumn{3}{|l|}{ Seasonal } \\
\hline Hot (March to May) & 39 & $(12.8)$ \\
\hline Wet (June to October) & 246 & $(80.9)$ \\
\hline Cool (November to February) & 19 & $(6.3)$ \\
\hline \multicolumn{3}{|l|}{ Type of first health care provider visited } \\
\hline Direct admission to hospital & 57 & $(18.8)$ \\
\hline Government doctor & 9 & $(3.0)$ \\
\hline Private doctor & 26 & $(8.5)$ \\
\hline BHS and paramedical staff & 7 & (2.3) \\
\hline $\begin{array}{l}\text { Pharmacy, untrained person, self- } \\
\text { medication }\end{array}$ & 32 & $(10.5)$ \\
\hline Station or township hospital & 31 & $(10.2)$ \\
\hline Places not specified & 142 & $(46.7)$ \\
\hline \multicolumn{3}{|l|}{ Cause of death } \\
\hline DSS & 257 & $(84.5)$ \\
\hline EDS & 40 & $(13.3)$ \\
\hline Dengue encephalitis & 5 & $(1.6)$ \\
\hline Others & 1 & $(0.3)$ \\
\hline Not recorded & 1 & $(0.3)$ \\
\hline
\end{tabular}

DHF, dengue hemorrhagic fever; DSS, dengue shock syndrome; EDS, expanded dengue shock syndrome; BHS, basic health staff.

${ }^{*}$ Station hospital = hospital covering villages in a township; township hospital = hospital covering whole township; district hospital = hospital covering the whole district; regional hospital $=$ hospital covering the whole state/region; teaching hospital $=$ hospital that provides medical education and training to health professionals; tertiary hospital = hospital providing tertiary care, which is health care from different specialists.

$(60.5 \%)$ were among females. The median age was six (IQR: 3, 9) years, $233(76.6 \%)$ deaths were among children $(<10$ years) and $246(80.9 \%)$ were reported during the wet (June to October) season. Dengue shock syndrome at admission was seen in 169 (55.6\%) and at death in 257 (84.5\%). Of 304 deaths, 36 (11.8\%) were reported from the township level hospital or below and the remaining were from higher level facilities.

The type of first health provider visited after fever onset was not recorded for $142(46.7 \%)$ patients and 57 (18.8\%) got directly admitted to hospital where they died. Among patients who had a first health care provider visit (that was recorded) before getting admitted to the hospital where they died $(n=105)$, $32(30.5 \%)$ either went to a chemist or untrained provider or self-medicated (Table 2). 
Diagnosis delay after fever onset

The date of onset of fever was only available for $208(68.4 \%)$ patients. Of these 208, the patients were admitted after a median of four (IQR: 3, 5) days after fever onset. The median patient level delay was three (IQR: 1,4) days and median health system level diagnosis delay was zero (IQR: 0, 2) days. Total diagnosis delay was four (IQR: 3, 5) days (Table 3).

Of 304, $81(26.6 \%)$ patients died within 24 hours of admission. Before admission, dengue fever was diagnosed in only $26(8.5 \%)$ (Figure 1).

\section{Discussion}

This is the first published study from Myanmar that described diagnosis delay from fever onset among all reported dengue deaths in Myanmar.

Most of the patients did not have a diagnosis of dengue fever before admission and more than half of the patients were in shock at admission. This was also seen in a study from Malaysia ${ }^{20}$. In Brazil, among patients with severe dengue, having a laboratory diagnosis was associated with a lower chance of dying when compared to not having a diagnosis ${ }^{21}$.
Absence of or delay in dengue fever diagnosis or lack of suspicion of dengue before admission may not have given time for proper treatment. The patients may have self-referred or were referred to higher level facilities when clinical features worsened, resulting in patients directly presenting with severe dengue at hospitals. Early diagnosis could have ensured detection of patients who were more prone to develop dengue haemorrhagic fever and dengue shock syndrome. Complications or worsening of dengue usually occurs at or after four days of fever onset ${ }^{8,23}$. This is when the fever also subsides.

Patient level delay (median three days) was a major contributor to the total diagnosis delay. Studies from Myanmar have reported that most people with fever sought care from untrained personnel or self-medicated and the reasons for avoiding care from trained health care providers (basic health staff, village health volunteers) was that minimal action was taken if fever patients were not diagnosed with malaria ${ }^{24,25}$.

The training for doctors and basic health staff on updated dengue guidelines was done only in 2018 and all regions were not covered. This could have contributed to the lack of clinical suspicion of dengue in peripheral health facilities.

Table 3. Diagnosis delays and admission time among dengue deaths reported to the national programme in Myanmar (2017-18).

\begin{tabular}{|l|l|l|l|l|}
\hline Delay & Times taken (days) between & N $^{*}$ & Median & (IQR) \\
\hline Patient level diagnosis delay & Onset of fever and first healthcare provider visit & 130 & 3 & $(1,4)$ \\
\hline Health system level diagnosis delay & First healthcare provider visit and diagnosis & 149 & 0 & $(0,2)$ \\
\hline Total diagnosis delay & Onset of fever and diagnosis & 206 & 4 & $(3,5)$ \\
\hline Time to admission & Onset of fever and admission & 208 & 4 & $(3,5)$ \\
\hline Admission time & Admission and death (hospital stay) & 304 & 1 & $(0,2)$ \\
\hline
\end{tabular}

IQR, interquartile range.

*Includes those for whom dates were available.

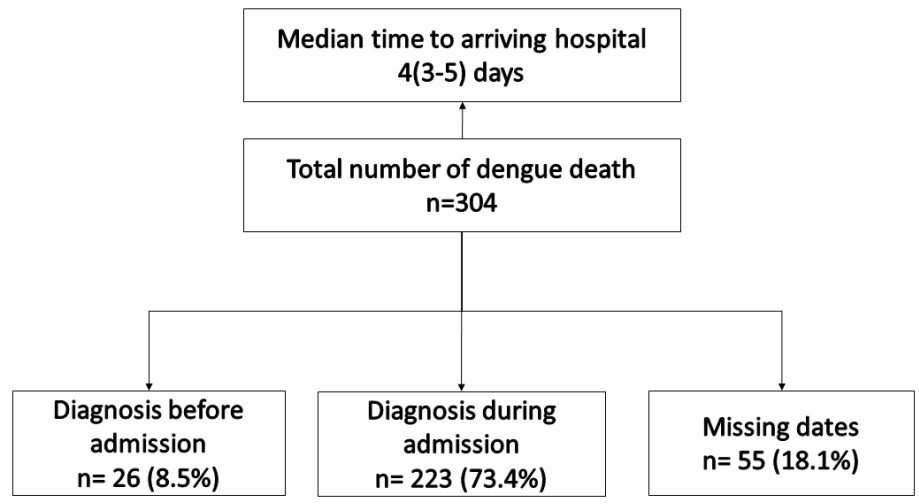

Figure 1. Timing of dengue diagnosis in relation to hospital admission among dengue deaths reported to the national programme in Myanmar (2017-18). 
The highest numbers of patients were reported in the wet season and were from the less than 10 years old age group. This highly correlates with the epidemiology of dengue disease $e^{2,5}$. The rainy season is also the school start time in Myanmar.

\section{Implications for policy and practice}

This study has five implications for policy and practice. First, a review of health system preparedness to suspect, diagnose, monitor, refer and treat dengue is required at peripheral health facilities as most patients were admitted without a diagnosis of dengue fever. This includes review of availability of rapid test kits at station hospitals and above. Considering the burden of dengue is similar to malaria in Myanmar, availability of test kits should be ensured at the level of station hospitals and preferably up to the grass roots level for evaluation of undifferentiated fever ${ }^{17}$. Training of basic health staff and doctors of all regions regarding the updated 2018 national guidelines is required. Guidelines for the management of undifferentiated fever should be developed ${ }^{26}$. This will especially be beneficial for health care providers in peripheral health facilities.

Second, as death investigation forms were not filled out in the prescribed format for all dengue deaths, we recommend quarterly dengue death reviews at regional and national levels. This will indirectly ensure that states and regions fill out the dengue investigation forms in the prescribed format and submit them to the VBDC Programme regularly.

Third, we recommend a similar study among all the reported dengue patients to confirm whether these findings are present (or not). Fourth, to address patient level delay there is a need to raise awareness in the community regarding health seeking for undifferentiated fever. Finally, the following four indicators may be added to the monthly forms in the health management information system in health facilities: i) total suspected with dengue ii) total confirmed dengue and iii) diagnosis within three days of fever among confirmed dengue.

\section{Strengths and limitations}

We collected nationwide data of all reported dengue deaths and this represents the ground reality. Data were robust as they were double entered and validated.

There were two major limitations in the study. First, death investigation forms were not being filled out. The reason for this is not known. This resulted in many missing variables as these were not available in the hospital case records. This includes details on the first health care provider visited and various dates. Diagnosis delay related findings are limited by the absence of the date of fever onset in one-third of patients. These forms also help the programme at a national level to review the causes of death, identify preventable health system related causes and take timely action.

Second, the variables recorded in hospital represent the clinical condition of the patients and other important variables for dengue prevention and control such as previous episodes of dengue, comorbidities, housing, income, occupation/school places, travel history, utilization of bed net, use of mosquito repellent were not routinely available.

To conclude, this study reported a long diagnosis delay after fever onset among dengue deaths reported over two years in Myanmar. This calls for an urgent review of health system preparedness to suspect, diagnose, monitor, refer and treat dengue at peripheral health centres and patient level factors for better understanding of reasons for diagnosis delay. Filling out of dengue death investigation forms should be ensured and corrective action be taken through regular regional and national dengue death reviews.

\section{Data availability}

Underlying data

Figshare: Nwe Ni Linn et al 2020 dataset v2. https://doi.org/10.6084/ m9.figshare.12355958.v $1^{27}$

This project contains the following underlying data:

- Data_NNL.xlsx (all de-identified variables extracted for this study, alongside a codebook explaining all fields and field values).

Data are available under the terms of the Creative Commons Zero "No rights reserved" data waiver (CC0 1.0 Public domain dedication).

\section{Disclaimer}

The views represented here are those of the authors and do not represent the institutions they are affiliated to.
1. Brady OJ, Gething PW, Bhatt S, et al:: Refining the global spatial limits of dengue virus transmission by evidence-based consensus. PLoS Negl Trop Dis. 2012; 6(8): e1760.

PubMed Abstract | Publisher Full Text | Free Full Text

2. Bhatia R, Dash AP, Sunyoto $\mathrm{T}$ : Changing epidemiology of dengue in South-East Asia. WHO South East Asia J Public Health. 2013; 2(1): 23-27. PubMed Abstract | Publisher Full Text

3. World Health Organization (WHO): Comprehensive guidelines for prevention and control of dengue and dengue haemorrhagic fever. World Health Organization. Regional office for South-East Asia. Geneva, Switzerland; 2011. Reference Source

4. World Health Organization (WHO): Dengue and severe dengue fact sheet 2019
[Internet]. 2019.

Reference Source

5. Anders KL, Nguyet NM, Chau NVV, et al:: Epidemiological factors associated with dengue shock syndrome and mortality in hospitalized dengue patients in Ho Chi Minh City, Vietnam. Am J Trop Med Hyg. 2011; 84(1): 127-34. PubMed Abstract | Publisher Full Text | Free Full Text

6. World Health Organization: Global Strategy for Dengue Prevention and Control 2012-2020. World Health Organiszation. Geneva, Switzerland; 2012. Reference Source

7. World Health Organization (WHO): Handbook for clinical management of dengue. Geneva, Switzerland; 2012. Reference Source 
8. World Health Organization (WHO): Global strategy for dengue prevention and control 2012-20. Geneva, Switzerland; 2012.

Reference Source

9. Sacramento RHM, de Melo Braga DN, Sacramento FF, et al.: Death by dengue fever in a Brazilian child: a case report. BMC Res Notes. 2014; 7: 855 PubMed Abstract | Publisher Full Text | Free Full Text

10. Jain S, Mittal A, Sharma SK, et al:: Predictors of Dengue-Related Mortality and Disease Severity in a Tertiary Care Center in North India. Open forum Infect Dis. 2017; 4(2): ofx056

PubMed Abstract | Free Full Text

11. Thein TL, Leo YS, Fisher DA, et al.: Risk factors for fatality among confirmed adult dengue inpatients in Singapore: a matched case-control study. PLOS One. 2013; 8(11): e81060.

PubMed Abstract | Publisher Full Text | Free Full Text

12. World Health Organization (WHO): Dengue: Guidelines for diagnosis, treatment, prevention and control. Geneva, Switzerland; 2009. Reference Source

13. Oo PM, Wai KT, Harries AD, et al.: The Burden of Dengue, Source Reduction Measures, and Serotype Patterns in Myanmar, 2011 to 2015-R2. Trop Med Health. BioMed Central; 2017; 45: 35.

PubMed Abstract | Publisher Full Text | Free Full Text

14. Department of Population; Ministry of Labour Immigration and Polpulation; Myanmar. Census Atlas Myanmar: The $\mathbf{2 0 1 4}$ Myanmar Population and Housing Census. Nay Pyi Taw; 2014.

Reference Source

15. Ministry of Health and Sports: Health in Myanmar, 2014. Nay Pyi Taw,Myanmar 2014

Reference Source

16. Ministry of Health and Sports; Myanmar: Paediatric Management Guidelines. Nay Pyi Taw, Myanmar; 2018.

17. World Health Organization (WHO): Comprehensive guidelines for prevention and control of dengue and dengue haemorrhagic fever. Geneva, Switzerland; 2011.

Reference Source
18. Ministry of Health and Sports; Myanmar: National Guideline for Clinica Management of Dengue. Nay Pyi Taw; 2018. Reference Source

19. Ministry of Health and Sports; Myanmar: Dengue Prevention and Control for BHS at Township Level. Nay Pyi Taw, Myanmar: Ministry of Health and Sports; 2018

20. Woon YL, Hor CP, Hussin N, et al.: A Two-Year Review on Epidemiology and Clinical Characteristics of Dengue Deaths in Malaysia, 2013-2014. PLOS Negl Trop Dis. 2016; 10(5): e0004575.

PubMed Abstract | Publisher Full Text | Free Full Text

21. Moraes GH, de Fátima Duarte E, Duarte EC: Determinants of mortality from severe dengue in Brazil: a population-based case-control study. Am J Trop Med Hyg. 2013; 88(4): 670-6.

PubMed Abstract | Publisher Full Text | Free Full Text

22. Makroo RN, Raina V, Kumar P, et al.: Role of platelet transfusion in the management of dengue patients in a tertiary care hospital. Asian J Transfus Sci. 2007; 1(1): 4-7. PubMed Abstract | Publisher Full Text | Free Full Text

23. Md-Sani SS, Md-Noor J, Han WH, et al.: Prediction of mortality in severe dengue cases. BMC Infect Dis. BMC Infectious Diseases; 2018; 18(1): 232. PubMed Abstract | Publisher Full Text | Free Full Text

24. Naing PA, Maung TM, Tripathy JP, et al.: Awareness of malaria and treatmentseeking behaviour among persons with acute undifferentiated fever in the endemic regions of Myanmar. Trop Med Health. BioMed Central; 2017; 45: 31. PubMed Abstract | Publisher Full Text | Free Full Text

25. Hein KT, Maung TM, Htet KKK, et al:: Low uptake of malaria testing within 24 $\mathrm{h}$ of fever despite appropriate health-seeking among migrants in Myanmar: mixed-methods study. Malar J. 2018; 17(1): 396.

PubMed Abstract | Publisher Full Text | Free Full Text

26. Bhargava A, Ralph R, Chatterjee B, et al:: Assessment and initial management of acute undifferentiated fever in tropical and subtropical regions. BMJ. 2018, 363: k4766.

PubMed Abstract | Publisher Full Tex

27. Shewade HD: Nwe Ni Linn et al $\mathbf{2 0 2 0}$ dataset v2. figshare. Dataset. 2020 http://www.doi.org/10.6084/m9.figshare.12355958.v1 


\section{Open Peer Review}

\section{Current Peer Review Status:}

\section{Version 1}

Reviewer Report 15 July 2020

https://doi.org/10.5256/f1000research.26148.r64470

(C) 2020 Zangmo S et al. This is an open access peer review report distributed under the terms of the Creative Commons Attribution License, which permits unrestricted use, distribution, and reproduction in any medium, provided the original work is properly cited.

\section{Sangay Zangmo}

Royal Centre for Disease Control, Ministry of Health, Thimphu, Bhutan

Lila Maya

Royal Centre for Disease Control, Ministry of Health, Thimphu, Bhutan

This manuscript projects interesting findings and correlations on diagnosis delay with deaths of dengue patients in Myanmar. For a country with high dengue burden, interventions on such findings will greatly enhance dengue diagnosis, referral, timely treatment and patient survival. Methods are clearly elucidated; strengths and weaknesses have been described well. Language and command in general is good, however, may need to be re-looked into in some sentences. I have some suggestions as below:

1. In the abstract: Most of the patients who died did not have a diagnosis of dengue before admission. This Sentence needs rephrasing.

2. In the introduction:

Dengue death is commonly associated with co-morbidities and clinicians should be aware if dengue patients fulfil the severe case definition on admission. Word "severe" may be in inverted commas

3. In the methods:

Doctors are first available at sub-township level station hospitals.

Remove "first"

Some general comments:

1. Definition of "delay" is not clear. After how many days would it be considered as delayed? In table 3, would it be more appropriate to use the word "duration" since there is no clear definition as to from which day "delay" would imply?

2. Ecological factors in this manuscript described include rainfall. Rainfall can be one of the factors among other such as temperature, vegetation and urbanization. Information on these variables, if available may be interesting. Some papers have been cited for your reference. 
3. In the discussion: Most of the patients did not have a diagnosis of dengue fever before admission and more than half of the patients were in shock at admission.

Does that mean patient previously visited some kind of health centres prior to admission? For those that were diagnosed, how was the diagnosis made?

\section{References}

1. Tsheten T, Clements ACA, Gray DJ, Wangchuk S, et al.: Spatial and temporal patterns of dengue incidence in Bhutan: a Bayesian analysis.Emerg Microbes Infect. 2020; 9 (1): 1360-1371 PubMed

Abstract | Publisher Full Text

Is the work clearly and accurately presented and does it cite the current literature?

Partly

Is the study design appropriate and is the work technically sound?

Yes

Are sufficient details of methods and analysis provided to allow replication by others? Yes

If applicable, is the statistical analysis and its interpretation appropriate? Yes

Are all the source data underlying the results available to ensure full reproducibility? Yes

Are the conclusions drawn adequately supported by the results?

Yes

Competing Interests: No competing interests were disclosed.

Reviewer Expertise: Molecularand virological techniques, Molecular epidemiology

We confirm that we have read this submission and believe that we have an appropriate level of expertise to confirm that it is of an acceptable scientific standard, however we have significant reservations, as outlined above.

Reviewer Report 03 July 2020

https://doi.org/10.5256/f1000research.26148.r65627

(C) 2020 Chong Z. This is an open access peer review report distributed under the terms of the Creative Commons Attribution License, which permits unrestricted use, distribution, and reproduction in any medium, provided the original work is properly cited. 


\begin{abstract}
Zhuo Lin Chong
Institute for Public Health, National Institutes of Health, Ministry of Health, Kuala Lumpur, Malaysia
\end{abstract}

Title and abstract: Reflective of the content

Introduction: The study is important. It would be perfect if the flow of the introduction can be rearranged to make the justification of the study stands out. Beside that, there were many references to adults and children in the text, with emphasis on the latter. Suggest to realign them to better reflect the title and content of the article.

Objectives: They are clearer in the abstract but in not the main text. Suggest to detail them out in the main text as well.

\title{
Methods:
}

1. Setting: The second paragraph on the availability of healthcare personnel is important in the interpretation of this study. Suggest making it clearer to readers not familiar with Myanmar healthcare system. E.g. replace the below hospital and center in bracket with an additional sentence right after the mention of sub-township level station hospitals to make clear the organisation.

2. Variables and data collection: Would be great if more details are given on the data collector/extractor, any quality control in place, how missing values were handled.

\section{Results:}

1. Suggest to state if the number of dengue death extracted for this study matched the number of death reported to VBDC through surveillance. Response rate is important to assess selection bias.

2. Table 2: Type of first health care provider visited has categories that overlap each other, e.g. directly admitted into hospital and government doctor can be the same thing. Please label the categories more distinctively. Would be perfect if they are also defined in the operational definition.

3. Patient profile of dengue deaths: Suggest: i) to remove "Among patients who had a first health care provider visit (that was recorded) before getting admitted to the hospital where they died ( $n=105) "$, ii) use $32(10.5 \%)$, and iii) use "pharmacist" instead of chemist. Discrepancies can create confusion and reduce readability.

4. Figure 1 Timing of dengue diagnosis: If the objective for this comes in second, suggest to present it in the same way. Consider additional subsection corresponding to the objective. Also, number and percentage of patients who died within 24 hours of admission could not be found in this figure.

5. Diagnosis delay after fever onset: Suggest to convert this table into a figure featuring a horizontal bar, on the left end of which labelled fever onset, the right end - death, and each stage in between. Then put your N, median, and IQR below with tracking lines going

\section{Discussion:}

upward to different stages on the bar. That way it is understandable at a glance. 
1. 2nd paragraph: "Most of the patients did not have a diagnosis of dengue fever before admission and more than half of the patients were in shock at admission. This was also seen in a study from Malaysia." Please make it clear that the reference to Malaysia is pointing to "shock at admission" and not "did not have a diagnosis of dengue fever before admission". As $73.6 \%$ of patients were suspected to have dengue in the Malaysian study.

2. The first section of discussion can be strengthened by comparing the results of this study with that of the other studies in depth.

3. Implication for policy and practice: Strengthening the discussion in the first section would make these recommendations more persuasive. Suggest to add good practices from other countries to make it compelling.

References: To reorganize references. Combine identical item into one reference, e.g. WHO Global Strategy 2012 in references 6 \& 8.

Is the work clearly and accurately presented and does it cite the current literature? Partly

Is the study design appropriate and is the work technically sound? Yes

Are sufficient details of methods and analysis provided to allow replication by others? Yes

If applicable, is the statistical analysis and its interpretation appropriate? Yes

Are all the source data underlying the results available to ensure full reproducibility? Yes

Are the conclusions drawn adequately supported by the results? Yes

Competing Interests: No competing interests were disclosed.

Reviewer Expertise: Evaluation of dengue rapid diagnostic test kits, dengue surveillance

I confirm that I have read this submission and believe that I have an appropriate level of expertise to confirm that it is of an acceptable scientific standard.

Reviewer Report 18 June 2020

https://doi.org/10.5256/f1000research.26148.r64469

(c) $2020 \mathrm{Xu}$ J et al. This is an open access peer review report distributed under the terms of the Creative Commons Attribution License, which permits unrestricted use, distribution, and reproduction in any medium, provided the original work is properly cited. 
Hui Liu

Yunnan Institute of Parasitic Diseases, Puer, China

Jian-Wei Xu

Yunnan Institute of Parasitic Diseases, Pu'er City, China

Dengue is now ranking as one of the most critical global mosquito-borne viral diseases and is endemic in over 100 countries. For many countries, dengue is becoming a threat to their public health, and further adversely impacting their health services and economies. Early diagnosis and effective supporting treatment for dengue can reduce transmission and improve patient prognosis. Data on death, delayed treatment are rare. This paper gives reader a profile and diagnosis delays in Myanmar. It is value to get indexed.

However, we suggest the author consider:

1. The part of introduction is not strong enough, not make the objectives clear.

2. "Most of the patients who died did not have a diagnosis of dengue before admission", please make clear in method section, "how were these patients confirmed as dengue ? just based on records of symptoms or have laboratory test evidence?

3. More discussing in detail on reasons of delayed diagnosis and potential solution, this will be significance on dengue control in Myanmar.

\section{References}

1. Harapan H, Michie A, Yohan B, Shu PY, et al.: Dengue viruses circulating in Indonesia: A systematic review and phylogenetic analysis of data from five decades.Rev Med Virol. 29 (4): e2037 PubMed Abstract | Publisher Full Text

Is the work clearly and accurately presented and does it cite the current literature? Partly

Is the study design appropriate and is the work technically sound? Partly

Are sufficient details of methods and analysis provided to allow replication by others? Yes

If applicable, is the statistical analysis and its interpretation appropriate? Yes

Are all the source data underlying the results available to ensure full reproducibility? Yes

Are the conclusions drawn adequately supported by the results? Yes 
Competing Interests: No competing interests were disclosed.

Reviewer Expertise: Control of vector borne diseases

We confirm that we have read this submission and believe that we have an appropriate level of expertise to confirm that it is of an acceptable scientific standard.

The benefits of publishing with F1000Research:

- Your article is published within days, with no editorial bias

- You can publish traditional articles, null/negative results, case reports, data notes and more

- The peer review process is transparent and collaborative

- Your article is indexed in PubMed after passing peer review

- Dedicated customer support at every stage

For pre-submission enquiries, contact research@f1000.com 